\title{
Paradoxical Tuberculomas Complicating Tuberculous Meningitis: About Two Cases
}

\author{
Cherkaoui Mandour ${ }^{1}$ Jawad Laaguili ${ }^{1}$ Miloudi Gazzaz ${ }^{1} \quad$ El Mostarchid Brahim \\ ${ }^{1}$ Department of Neurosurgery, Military Hospital Mohammed V, \\ Rabat, Morocco

\begin{abstract}
Address for correspondence Cherkaoui Mandour, MD, Department of Neurosurgery, Military Hospital Mohammed V, Street hay ryad; zip code: 10000; Rabat, Morocco
\end{abstract} \\ (e-mail: mandour1978@hotmail.com).
}

Indian J Neurosurg 2018;7:51-53

\begin{abstract}
Keywords

- tuberculoma

- paradoxical

- meningitis

Paradoxical tuberculomas in patients with tuberculous meningitis during antituberculous chemotherapy is an unusual phenomenon. This reaction is due to the immune response of the host to antituberculous drugs. It is commonly seen in the intensive phase of chemotherapy. We report the cases of two patients with tuberculous meningitis who had developed tuberculomas during adequate and appropriate antitubercular therapy. Tuberculous meningitis requires the regular clinical and radiological follow-up to detect paradoxical response.
\end{abstract}

\section{Introduction}

Tuberculosis remains one of the common infectious diseases of the central nervous system (CNS) in Africa. Paradoxical development of intracranial tuberculomas during treatment of tuberculous meningitis was occasionally reported, presenting with symptoms of an intracranial space occupying lesion. ${ }^{1,2}$ We present the cases of two patients who developed intracranial tuberculomas during antituberculous chemotherapy.

\section{Case 1}

A 23-year-old woman was followed-up for 7 months for tuberculous meningitis. She was treated with antituberculous chemotherapy. She was admitted for headache and lower left visual acuity with normal neurological examination. A magnetic resonance imaging (MRI) T1 weighted after injection of gadolinium showed a left para sella tuberculoma with ringed or nodular enhancement ( - Fig. 1: Panel A). The patient was operated by a computed tomography (CT)guided stereotactic aspiration and biopsy ( - Fig. 1: Panel B).

\section{Case 2}

A 26-year-old woman underwent antituberculous treatment for 9 months of tuberculous meningitis. Neurological examination at admission revealed discrete headache associated with psychiatric disorders (depression), without neurological deficit. An MRI T1 weighted after injection of gadolinium showed a multiple nodular lesions with ringed enhancement ( -Fig. 2: Panel A). The patient was operated by a CT-guided stereotactic aspiration and biopsy ( - Fig. 2: Panel B).

\section{Discussion}

Paradoxical development of intracranial tuberculomas during treatment of tuberculous meningitis is an exceptional clinical presentation. This phenomenon is defined as appearance of new symptoms or radiographic manifestations of tuberculosis that occur after initiation of treatment and are not the result of treatment failure. ${ }^{3}$ In our patients, CT scan of the brain was performed at the time of the diagnosis of tuberculous meningitis and it was normal.

The explanation is not irregular medicines, ${ }^{4}$ but now it is increasingly being recognized as a cause of subsequent deterioration in cases of CNS tuberculosis despite adequate and appropriate therapy, ${ }^{3,5,6}$ without an immune deficiency, such as in our patients, human immunodeficiency virus (HIV) test was negative. $^{7}$

Various hypotheses have been put forward to explain this reaction, drug resistance, or failure of drugs to penetrate the blood-brain barrier. It has been proposed that paradoxical reaction is the result of a disturbance in the immunity of the patient while responding to the treatment. ${ }^{5}$ Tuberculostatic drugs cause the destruction of mycobacterial structures and

\section{received}

January 14, 2016 accepted after revision

March 11, 2016

published online

April 12, 2017
DOI https://doi.org/

10.1055/s-0036-1585426. ISSN 2277-954X.
Copyright @2018 Neurological

Surgeons' Society of India
License terms

$($ () (1) $\ominus \circledast$ 
A

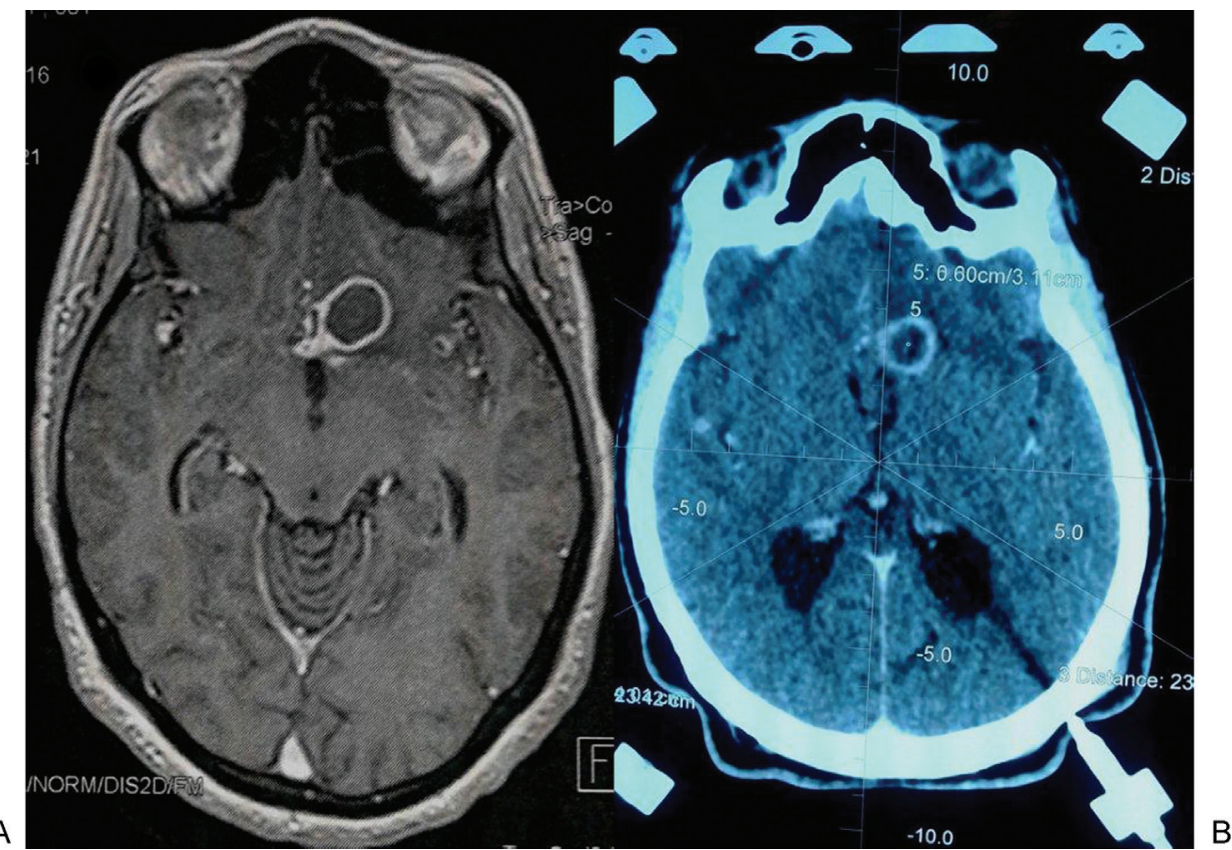

Fig. 1 (A) Axial magnetic resonance imaging T1 weighted after injection of gadolinium showed a left parasellar tuberculoma with ringed or nodular enhancement. (B) Computed tomography of the brain with injection of contrast during stereotactic biopsy.

emit bacillary mycobacterial proteins, leading to the presence of inflammation and hypersensitivity. ${ }^{1,8}$

Tuberculomas usually emerge after about 3 months of treatment, though the interval has been as short as 30 days and as long as 12 months. ${ }^{19}$ These lesions are discovered accidentally when follow-up brain imaging is performed routinely or when new neurologic signs develop during the course of antituberculous therapy. In our cases, the appearance of neurological symptoms led to the discovery of these lesions.

Any course of antituberculosis chemotherapy should be completed, and intracranial pressure should be controlled.
Adjunctive therapy with steroids appears to diminish neurological symptoms and may improve outcome. ${ }^{10}$ These patients should probably be kept under observation for several years.

\section{Conclusion}

It is necessary to keep in mind that meningitis tuberculous may be complicated by a paradoxical expansion of a tuberculoma, despite appropriate therapy, hence the interest and the importance of regular clinical and radiological follow-up.

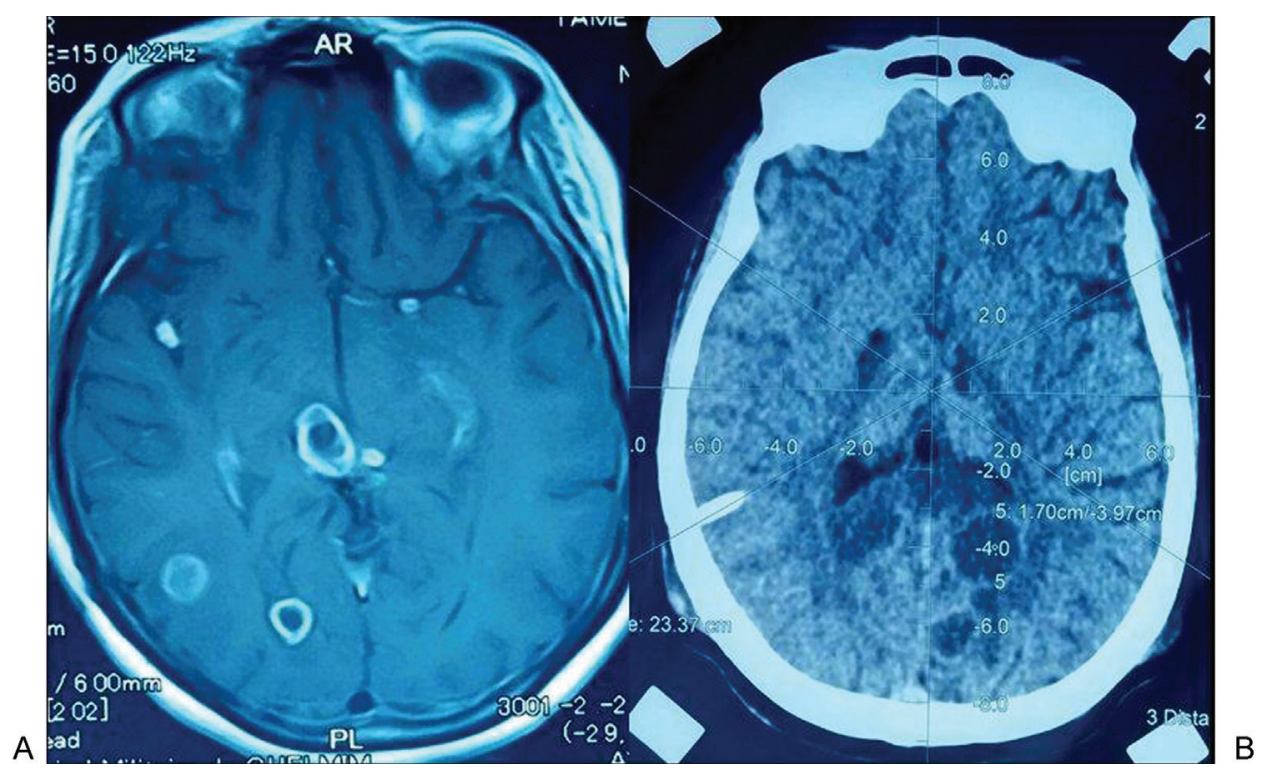

Fig. 2 (A) Axial magnetic resonance imaging T1 weighted after injection of gadolinium showed a multiple nodular lesions with ringed enhancement. (B) Computed tomography of the brain with injection of contrast during stereotactic biopsy. 


\section{References}

1 Lees AJ, MacLeod AF, Marshall J. Cerebral tuberculomas developing during treatment of tuberculous meningitis. Lancet 1980;1(8180):1208-1211

2 Malik GM, Mubarik M, Basu JA, Kadla SA, Hussain T, Rashid S. Paradoxical expansion of cerebral tuberculomas during therapy for Pott's spine. J R Soc Med 1996;89(11):643-644

3 Gupta M, Bajaj BK, Khwaja G. Paradoxical response in patients with CNS tuberculosis. J Assoc Physicians India 2003;51:257-260

4 Shah I, Borse S. Paradoxical tuberculomas after completion of antituberculous treatment. Trop Med Health 2012;40(1):15-17

5 Dubé MP, Holtom PD, Larsen RA. Tuberculous meningitis in patients with and without human immunodeficiency virus infection. Am J Med 1992;93(5):520-524

6 Chambers ST, Hendrickse WA, Record C, Rudge P, Smith H. Paradoxical expansion of intracranial tuberculomas during chemotherapy. Lancet 1984;2(8396):181-184
7 Cheng V, Ho P, Lee R, et al. Clinical spectrum of paradoxical deterioration during antituberculosis therapy in non-HIVinfected patients. Eur J Clin Microbiol Infect Dis 2002;21(11): 803-809

8 Zavascki AP, Dias AE, Cruz RP, de Oliveira RL, Duquia RP. Intracranial tuberculomas in an immunocompetent patient mimicking brain metastasis of unknown origin. Infection 2006;34(3):181-182

9 Teoh R, Humphries MJ, O'Mahony G. Symptomatic intracranial tuberculoma developing during treatment of tuberculosis: a report of 10 patients and review of the literature. Q J Med 1987;63(241):449-460

10 Afghani B, Lieberman JM. Paradoxical enlargement or development of intracranial tuberculomas during therapy: case report and review. Clin Infect Dis 1994;19(6):1092-1099 